\title{
Causes and Social Implication of Migration to the Middle East (A Case Study of Village Zarobi/Swabi, Khyber Pakhtunkhwa)
}

\section{A. Gul (Ayesha Gul)', A. Naz (Arab Naz)ㄹ, N. Khan (Nasar Khan)3}

${ }^{1}$ Assistant Professor Social Work Department SBK Women's University Quetta, Balochistan, Pakistan

2 Professor Sociology Department University of Malakand, Khyber Pakhtunkhwa, Pakistan

${ }^{3}$ Lecturer Sociology Department University of Chitral, Khyber Pakhtunkhwa, Pakistan

\section{E-mail address:}

gul_aisha@hotmail.com

\section{Reprint address:}

Ayesha Gul

Social Work Dept. SBKWU University Balochistan

Bawrery Road, Quetta

Balochistan

Pakistan

Source: Clinical Social Work and Health Intervention

Volume: 10

Issue: 2

Pages: $43-52$

Cited references: 17

\section{Reviewers:}

Michael Costello

University of Scranton School of Education, USA

Zofia Szarota

Pedagogical University of Cracow, Poland

\section{Key words:}

Migration, Challenges. Un-employment. Corruption. Opportunities. Skilled. White Collar. Blue Collar. Self Employed.

\section{Publisher:}

International Society of Applied Preventive Medicine i-gap

CSWHI 2019; 10(2): 43 - 52; DOI 10.22359/cswhi_10_2_07 @ 2019 Clinical Social Work and Health Intervention 


\section{Abstract:}

Migration is the act of leaving one's native country or region to settle in another. There are many reasons why people might choose to emigrate. Many political or economic emigrants move together with their families toward new regions or new countries where they hope to find peace or job opportunities not available to them in their original location. Throughout history a large number of emigrants return to their homelands, often after they have earned sufficient money in the other country. Sometimes these emigrants move to countries with big cultural differences and will always feel as guests in their destinations, and preserve their original culture, traditions and language, sometimes transmitting them to their children. 26,604 engineers and 7,930 doctors had so far migrated to foreign countries. An estimated 52\% migrant workers are from Punjab, 25\% from the NWFP, 9.4\% from Sindh, 6.5\% from the Balochistan province, 5.4\% from FATA and 1\% from Azad Kashmir. Pakistan has a large pool of skilled manpower. It is cost-wise cheaper, considerably efficient and reliable, and can easily adapt to different cultures and conditions across the globe. A low level of domestic income for individuals results in lack of access to education, health care and other communal facilities like lack of sanitation, transportation and communication. The most consistent reason for migration has been poverty, lack of economic prospects and disparities in income levels. The Global Commission on International Migration has been discussing poverty as one of the main causes of migration. We believe migration provides an effective tool for addressing poverty. The current study focuses on the causes and social implications of migration of the people who migrated to Middle East for earning. The universe of the study is Zarobi/Swabi Village situated in Khyber Pakhtunkhwa from where the youth are rapidly migrating to the Middle East and Europe. The study is quantitative in nature; 86 respondents were interviewed through an Interview Schedule. Purposive Quota Sampling Technique was applied. The Accidental Sampling method was further applied while visiting houses. The first available emigrant was interviewed. The data is analyzed through SPSS and simple statistical tables. The study found that poverty, injustice and lack of job opportunities are the root causes of youth migration. The study recommends youth is the future of our nation and the government should accord priority to their welfare; should increase employment opportunities; establish political and security stability; offer a better standard of life.

\section{Background}

The act of movement from one country to another country is called emigration. Anyone who moves permanently to another geographic region of the same country and all who move permanently to another country can be defined as migrants. (John R. Weeks, 1985). The definition of migration can be confounded by the fact that migration is an 
activity (changing residence) carried out by people under varying legal and socio-political circumstances. (Abercrombie, Hill \& Turner 1988) Human migration denotes any movement by humans from one locality to another, sometimes over long distances or in large groups (Zafar, 2004). Labor migration was started from Pakistan in the 1950's after World War II when Europe was in need of manpower after the large scale death of people for the reconstruction of Europe. Migration is not a new phenomenon. It started after the creation of Hazrat Adam (A.S). For centuries, people have moved across borders for economic and political reasons. Large scale external labor migration has played a crucial part in the economic development of post-war Europe. Migration does not provide economic development for poor regions which remain underdeveloped and dependent on the centers industrial capitalism (Qaimkhani, 2005)

History of mankind is replete with the examples of people migrating from one country to another country either for permanent settlement or for a short duration in search of better social and economic life, but which kind of shoving and jostling is seen in Pakistan is extremely miserable and detrimental. (Zaidi, 2006)

Migration is a natural phenomenon, which has existed throughout the history. It has made immense contributions in the development of the human civilization. Migration has also presented numerous challenges for the societies and governments, because of the ever-increasing number of people moving across borders and the impact they have on the countries of their destination as well as origin. People have always migrated from one place to another for a variety of reasons. The most consistent reason for migration has been poverty, lack of economic prospects and disparities in income levels.
The Global Commission on International Migration has been discussing poverty as one of the main causes of migration. (Siddiqui, 2002). We believe migration provides an effective tool for addressing poverty, in particular through migrant remittances. Remittances help in alleviating poverty to some extent. While migrant remittances can stimulate development in the countries of origin, their overall impact on development has not been substantiated. They definitely cannot be a substitute to international development assistance.

\section{Migration and Pakistan}

Migration has been a constant in the history of Pakistan. From its inception, its people have been moving in migratory waves. This migration of people started with the moving of millions of people from India into Pakistan when the two nations gained their independence from British colonial rule. These Muslims moved to Pakistan in hopes of a better life, not just economically but socially and religiously as well. Pakistan has been receiving immigrants from the other parts of the Indian sub-continent. (Siddiqui, 2002) The migration to the Gulf began in the 1970s. Pakistan had a severe balance of payments deficit and so as a way of dealing with this deficit, the government of Zulfiqar Ali Bhutto encouraged both skilled and unskilled men to work in the Persian Gulf countries. The government set up a program under the Ministry of Labor Manpower and Overseas Pakistanis to regulate this migration. With the construction boom in the Gulf States at that time, labor jobs were plentiful and Pakistani men were more than willing to go. About 287,000 workers left Pakistan for abroad in 2007. (Donald, 1969) among the skilled workers; drivers were in the highest number followed by masons, carpenters and tailors. 26,604 engineers and 7,930 doctors had so far migrated to foreign countries. An 
estimated 52\% migrant workers are from Punjab, 25\% from the NWFP, 9.4\% from Sindh, $6.5 \%$ from the Balochistan province, 5.4\% from FATA and 1\% from Azad Kashmir. The demand for skilled and qualified workers is higher in the international market as compared to the demand for low/ unskilled workers. In 2007, about 47.76\% skilled and professional workers migrated to different countries. (Sheikh, 2003)

By the mid-1980s, when this temporary migration was at its height, there were an estimated 2 million Pakistanis in the Persian Gulf states making up the largest group of foreign workers. The majority of migrant workers are working-class men who travel alone leaving their wives and children behind. These men are willing to sacrifice years with their families for what they see as their only chance to escape poverty in a society with limited upward mobility.

Families generally use the overseas earnings for consumer goods rather than investing in industry. The wage earner typically returns after five to ten years to live at home (Sheikh, 2003).

Although this migration has had little effect on Pakistan demographically, it has affected its social fabric. While a man is away from his family, his wife often assumes responsibility for many day-to-day business transactions that are considered the province of men. For the women involved, therefore, there has been a significant change in social role. Psychologists point out that many migrant workers in the Middle East are profoundly affected. They tend to feel a sense of social isolation, culture shock, and are depressed by the harsh working conditions in these countries. They also suffer from a sense of disorientation resulting from the sudden acquisition of relative wealth and from the guilt associated with leaving their families. Pakistan being a developing country is confronting with, among others, the increasing problem of un-employment caused by rapid increase both in the population and labor force which has jolted the whole economy. As many as 3.27 million Pakistanis have proceeded abroad for employment duly registered with the offices of Protector of emigrants during the period from 1971 to 2003 (up to June). The Overseas Employment Promoters, in the private sector are playing a vital role in overseas employment. The migration flow of highly qualified professionals was started in 1990's and today it is on peak. The most despondent thing is that today left Pakistan they left it forever; no one wants to live here (Ilahi, Safdar \& Asad, 1993-94).

Poverty is one of the major social problems Pakistan is facing. It is one of the most important and sensitive issue not only for our self but for the whole world. Poverty can cause other social problems like theft, bribery, corruption, adultery, lawlessness, injustice. To eradicate the evils of society we have to fight poverty. We can't control theft by enrolling thousands of police men (Rana, 2004). Corruption and injustice can't come to an end through tight legislation but by demolishing poverty. Unemployment is undoubtedly the most important economic problem that confronts the country. Unemployment means the waste of man power, both skilled and unskilled. In simple term then we may say that unemployment is said to exist in a country where able bodied persons of working age, who are willing to work, are not able to find work at the current wage level (Khalid, 2003). According to the labor force survey (1996-97) the problem of unemployment and under-employment seems to have been here for a long time,. The problem of unemployment among the educated is not new. In recent years, no doubt, unemployment among the educated has assumed proportion (Khalid, 2003). 
The main reason unemployment among the educated is a general trend to look for employment in office jobs. As a result, those who have managed to get a college or university education hesitate to take a vocational job because it involves more physical labor (Rubenstein, 1983). According to a recent Gallup Pakistan survey, only 9\% of Pakistanis are hopeful of better times in 2009. In April 2008, over two months after the general elections, as many as $60 \%$ of Pakistanis had hoped things would improve. The problem of corruption is more acute in developing societies than in the developed world. There is not only wide spread but also causes more harm to the Government and society (Sheikh, 2003).

\section{Literature Review}

Ankrah Kwaku Twumasi (1995) Migration \& Socioeconomic Development in Gha$n a$ - This article discusses the case of Ghana where migration creates major changes in the social and behavioral patterns of migrant people when these migrants decide to shift their base due to availability of better education, healthcare facilities and entertainment and then this forces them to re-socialize their behaviors which ultimately leads to change in behavioral pattern.

Report on Migration by Department for International Development (2007) Moving out of Poverty - Making Migration Work Better for Poor People - This report discusses how migration can improve the economic conditions of poor people and hence reduce poverty. Although there are varioust reasons for migration, still today globalization plays a crucial role. Due to globalization, movement of resources becomes easier, thus it helps countries to reduce labor shortages and improves the standard of living among rural poor. At the national level, movement of people towards well developed areas can provide an opportunity to improve their living conditions.

Kuhn S. Randall (2005) The Determinants of Family \& Individual Migration A Case Study of Rural Bangladesh - This paper discusses the issue of migration considering the role of family as one of the important parameters. The individual migration decision is more likely among those who have less land holding, whereas in case of family migration, marriage of people and those who don't have any land holding are important determinants. These people tend to migrate along with their family members. The important aspect is that, after marriage chances of individual migration decreases and family migration increases.

\section{Objectives of the Study}

To know the causes and attitude of the youth towards migration.

To know the impact of migration on socio-economic condition of the concerned family.

\section{Study Design/Methodology}

Universe/Sampling: On the basis of the selected area (Zarobi Village), Purposive Quota Sampling Technique was applied. An accidental sampling method was further applied while visiting houses. The first available emigrant was interviewed.

\section{Tools for Data Collection}

Assuming that perhaps few respondents might be illiterate an interview schedule was adopted as a workable tool for primary data collection. For additional insight into the situation, observations of interviewers were also added into report. Secondary data was mustered separately through review of books, reports and surfing of websites. During data collection it was found that 
most of youth were eagerly interested to share their issues and concerns regarding impact and problems of migration. The process went smoothly. 86 Interview Schedules have been collected, which were serialized, minor errors were removed and master sheet was developed to proceed further into data analysis and report writing. The collected data was analyzed through statistical tools and detailed under the study report was prepared. Based upon the main findings of the study, suggestions and recommendations were made part the entire study.

\section{Results and Analysis}

Figure 1: Respondent's Age

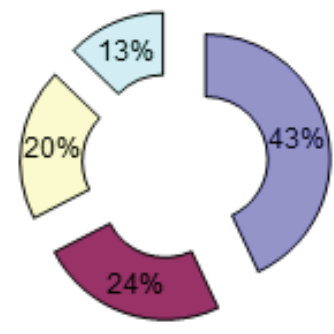

Half of respondents i.e. $43 \%$ were between the ages of 21 to 25 years, $24 \%$ of the respondents were between the ages of 26 to $30.20 \%$ of the respondents were of the ages of 31 to 35 . While, only $13 \%$ respondents were between the ages of 36 to 40 years.

Figure 2: Marital Status of Respondents

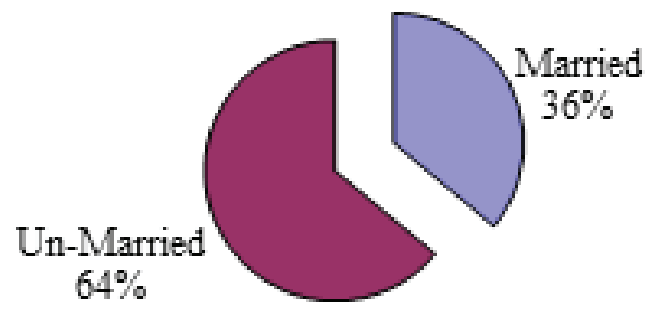

口Married $\square U_{n}-M a r r i e d$
According to the above majority of respondents i.e. $64 \%$ were un-married, while $36 \%$ of total respondents were married.

Figure 3: Countries where Respondents Migrated

No. of Respondents

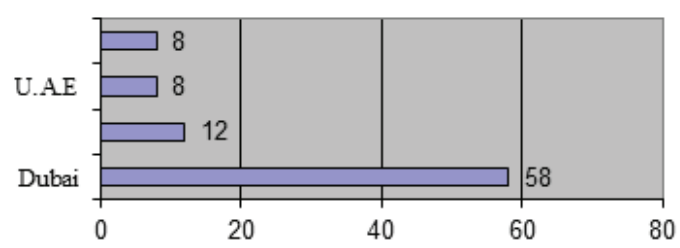

口No. of Respondents

Above table shows that large majority of respondents i.e. $68 \%$ had migrated to Dubai, whereas $14 \%$ of respondents had move to Kuwait, while $9 \%$ of total respondents migrated to U.A.E and Bahrain.

Figure 4: Skills of Emigrants

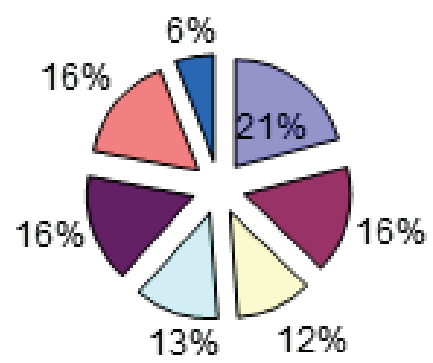

$\square a b \square c \square d \square e$ ㅁ $\square g$

\begin{tabular}{|l|}
\hline a. Carpenters \\
\hline b. Technicians \\
\hline c. Electricians \\
\hline $\begin{array}{l}\text { d. } \text { Welders/ Mechanics/ Air Condition } \\
\text { Mechanics }\end{array}$ \\
\hline e. Masons/ Skilled Construction Workers \\
\hline f. Different Type of Operators \\
\hline g. Plumbers/ Steel Fixers \\
\hline
\end{tabular}


According to above table most respondents i.e. $21 \%$ belonged to the profession of Carpenter, 16\% were Masons, technicians and different type of operators respectively. Whereas $13 \%$ respondents were welder/ mechanics, $12 \%$ of respondents were electricians. While only $6 \%$ of respondents were Plumbers and steel fixers.

Figure 5: Reason for Migration

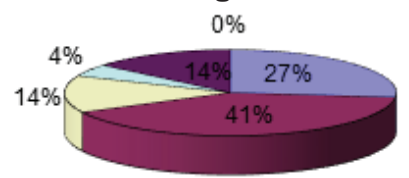

\begin{tabular}{ll|}
$\square$ Poverty & Un-employment \\
$\square$ Compitition with Cousins & $\square$ Forced by Parents \\
$\square$ More Income & $\square$ Learning/Education \\
\hline
\end{tabular}

Out of total a large majority of the respondents i.e. $40 \%$ replied they have migrated to abroad because of un-employment, $27 \%$ replied they moved abroad because of Poverty, $14 \%$ had competition with the cousins. $14 \%$ of others said they were in need to get more income. While, only $5 \%$ of respondents were forced by their parents to move abroad.

Figure 6: Job Profile Abroad

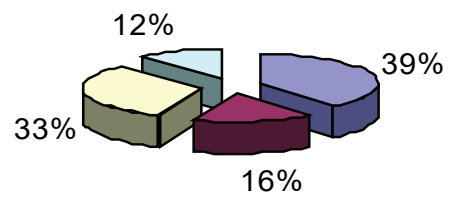

$\square$ Physical Labour $\square$ White Collar Job
$\square$ Blue Collar Job $\square$ Self Employed

Above table shows that large number of respondents i.e. 39\% was affiliated with Physical labor job, whereas $33 \%$ of total was with blue collar jobs, $16 \%$ of emigrants were busy in white collar job. While $12 \%$ of emigrants said they are self employed abroad.
Figure 7: How the Economic Condition of a Emigrant has Changed

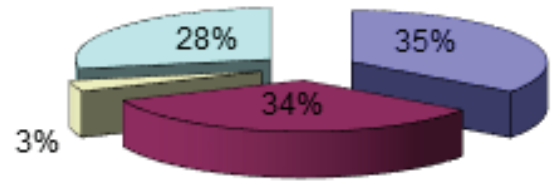
$\square$ Acquired own Property
Acquired good Residence in City/Villag e
$\square$ Started a Good Business
$\square$ Women Put on Golden Ornaments

This table indicates majority i.e. $35 \%$ of respondents have acquired their own property, 34\% have acquired good residence in cities and their villages, 28\% respondents women have put on golden ornaments. $3 \%$ of total respondents have established a good business.

Figure 8: Nature of Impacts on Children in Absence of Father

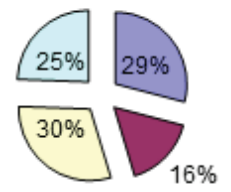

\begin{tabular}{|ll|}
\hline$\square$ Loafers \& Deliquent & $\square$ Depressed \\
$\square$ No Education & $\square$ No Control Over Children \\
\hline
\end{tabular}

Above data shows the majority of respondents i.e. $31 \%$ replied, in absence of father the children pay no attention to their education, $29 \%$ of respondents said children become loafers and delinquent, 24\% said mother cannot control the children alone and $16 \%$ respondents said in many cases children become depressed in absence of father and they usually miss their father. 
Figure 9: Additional Responsibilities Caused in the Role of Women

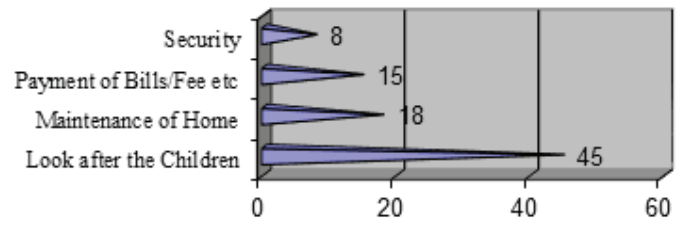

$\square$ Responsibilities

In this table majority respondents i.e. $53 \%$ replied, in additional responsibilities mother have to look after the children, second majority $21 \%$ said women have to look after the maintenance of home, $17 \%$ said in absence of husband mother has to pay the bills, fee etc. 9\% respondents said in this male dominant society lonely women face the problems of security in the absence of husband.

Figure 10: Recommendations to Reduce the Proportion of Overseas Migration
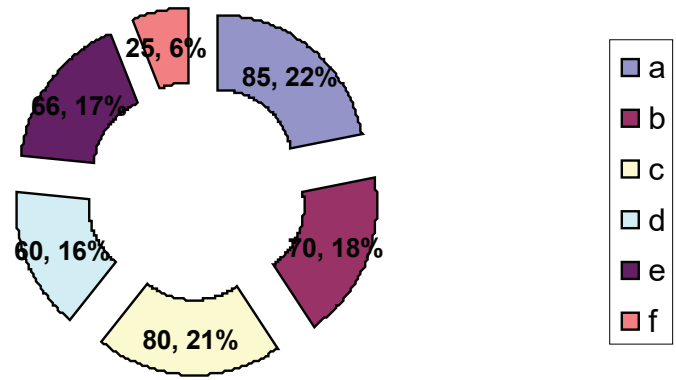

\section{Details of Legend.}

a. Better Job Opportunities should be Provided

b. Better Law and Order Situation should be maintain in the Country

c. Good Salary Packages and Incentives

d. Merit and Justice

e. Access to Basic Human Needs

f. Promotion and Encouragement of Multinational Companies.
Majority of respondents i.e. $22 \%$ recommended stopping or decreasing the migration of man power from Pakistan it is needed to provide better job opportunities to the youth. $21 \%$ said good salary packages and incentives should be given to the youth, $18 \%$ said there is need of justice and open merit in the country, $17 \%$ respondents recommend that every individual should have access to the basic human needs, $16 \%$ answer was merit and justice while, $6 \%$ of respondents recommend Government should encourage and promote the multinational companies and investments.

\section{Discussion}

Pakistan has a large pool of skilled manpower. It is cost-wise cheaper; considerably efficient and reliable; can easily adapt to different cultures and conditions across the globe. The study finds that a major proportion of Pakistani migrant workers are in the Gulf region, as this part of the world has become a favorite destination. There might be some factors which influence the person to do this job unwillingly. The motivational factors, which makes a person leave his native place, are called push / pull factors. To the question as to the reason for migration, most respondents replied that unemployment is undoubtedly the most important economic problem that confronts the country. Unemployment means the waste of manpower, both skilled and unskilled, as confirmed from previous studies that the problem of unemployment among the educated is not new. In recent years, no doubt, unemployment among the educated has assumed some proportion (Meraj, 1979). Referring to the question regarding how the economic condition of the migrant has been changed, a large number replied that they have acquired their own property; many of them have acquired good residence in cities and their villages; and a large number of 
women have put on golden ornaments and a very small number of respondents have established a good business.

This was previously proved from a study that migration unemployment is reduced and people get better job opportunities. Migration helps in improving the quality of life of people (Rauf, 1984). This study identified that it is a fact that migrant workers abroad frequently involve the separations of families which is socially disruptive at home and which contributes to the rise of prostitution and homosexuality. Newly married women, who have been childless, return to their parents. This result, though lessened, was consistent with some previous research (Ilahi, Safdar \& Asad, 1993-94). Wives have to look after the children; send them to school; take care of their activities; also run their household affairs like buying the daily household materials; doing the jobs which had been done by male members. This process and the load of work leads towards physical and mental fatigue and this stress proceeds further when they visualize that the coming generation as becoming delinquent; holding alien values, moral ethics and family affairs. This finding is quite similar to early studies that showed that migration is one of the main causes for the decrease in nuclear family where children grow up without a wider family circle and sometime without a father forever (Zaidi, 2006). Their educational level decreased day by day. In response to recommendations most of the respondents proposed that to decrease the migration of manpower from Pakistan it is necessary to provide better job opportunities to the youth. $21 \%$ said good salary packages and incentives should be given to the youth; and some replied there is need for more open merit and justice in the country.

\section{Recommendations}

Based upon the findings of the study the following recommendations are put to solve the issue

- Youth is the future of our nation and the government should accord priority to their welfare; should increase the employment opportunities; establish political and security stability; a better standard of living.

- Economic and social problems, political and security reasons, and better standard of life were some of the reasons forcing people to migrate to other countries. So government should increase the employment opportunities; establish political and security stability; a better standard of living.

- Ensuring welfare of the families left behind, and ensuring social and economic re-integration of returned migrants so they can start their own earning means in the country.

- Government should take steps to enhance safe migration opportunities and abolition of irregular migration.

- Skilled and semi-skilled workers like technicians, electrician, welders, mechanics, drivers, cooks, air condition mechanics, different types of operators, nursing staff, skilled construction workers including masons, carpenters, plumbers and steel fixers, and skilled/ semi-skilled workers in food, vegetables and beverage industries should be payed a living wage.

\section{Conclusion}

The most consistent reason for migration has been Unemployment, poverty, lack of economic prospects and disparities in income levels. The Global Commission on International Migration has been discussing poverty as one of the main causes of migration. A low level of domestic income for the 
individual results in lack of access to education, health care and other communal facilities like lack of sanitation, transportation and communication. However, this study proved that unemployment is the root cause of migration to the Middle East. We believe migration provides an effective tool for addressing poverty. Injustice and lack of opportunities are further root causes of youth migration. Youth is the future of our nation and the government should accord priority to their welfare; should increase employment opportunities; establish social security and stability; provide a better standard of living.

\section{References}

1. RANA A A (2004) Ik aag ka darya hey aur doob key jaana hey, Daily Kohistan, Sunday Magazine, 10th Oct.

2. BOGUE D (1969) Principles of Demography, London, John Waley and Sons.

3. RAUF M A (1984) Rural-Urban Migration and Rural Emigration in Pakistan.

4. SHAIKH M H (2003) Principles of Public Administration Theory and Practice, Kifayat Academy.

5. KHALID M (2003) Social Problems of Pakistan, Kifayat Academy.

6. SIDDIQUI H A (2002) Prospects for Overseas Employment, Dawn News Paper.

7. MERAJ F (1979) Industrialization and Urbanization, Department of Social Work, University of Punjab.
8. http://citeseerx.ist.psu.edu/viewdoc/download?doi=10.1.1.454.7113\&rep=rep $1 \&$ type $=$ pdf.

9. http://pdfproc.lib.msu.edu/?file=/DMC/African\%20Journals/pdfs/social\%20development/vol10no2/jsda010002003.pdf.

10. http://www.sussex.ac.uk/Units/SCMR/drc/ publications/other_publications/Moving Out_of_Poverty.pdf.

11. RUBENSTEIN J M (1983) The Cultural Landscape" Merrill Publishing Company, Second edition, Miami University Oxford.

12. WEEKS J R (1985) 8 Population an Introduction to Concept and Issues, San Diego University, United States.

13. ABERCROMBIE N, HILL S, TURNER B S (1988) 2 Dictionary of Sociology, Allen Lane Penguin Books.

14. ILAHI K, SAFDAR S, ASAD A Z (199394) Social Implications of Migration and Labor to Middle East (A case study of Khall Distt. Dir), University of Peshawar.

15. ZAFAR R (2004) Chalo Chalo kahin bhi chalo, Mahnama Nawaye Insaan, 10th Dec. (2004).

16. QAIMKHANI R S (2005) Migration and development, Second standing committee of the $113^{\text {th }}$ IPU Assembly, Geneva.

17. ZAIDI S A (2006) The State of Pakistan Economy and the Federal Budget 2006-07, Aurat Foundation and Information Service Foundation. 